\title{
In search for relationships between lightning and rainfall with a rectangular grid-box methodology
}

\author{
S. C. Michaelides, K. Savvidou, K. A. Nicolaides, and M. Charalambous \\ Meteorological Service, Nicosia, Cyprus
}

Received: 2 December 2008 - Revised: 11 March 2009 - Accepted: 6 April 2009 - Published: 8 April 2009

\begin{abstract}
The rainfall and lightning activity associated with three depressions which affected the area of Cyprus were studied in order to identify possible relationships between them. The lightning data were provided by the National Observatory of Athens, Greece, and were spatially and statistically related to the corresponding rainfall measurements from the rain gauge network of the Cyprus Meteorological Service. The study was carried out by using a rectangular grid-box methodology and various combinations of lightning and rainfall data filtering and time-lags were tested.
\end{abstract}

\section{Introduction}

Lightning location systems have been in operation over Europe and the Mediterranean since the middle of the past century (then better known as "spherics"). The ZEUS lightning system is a modern network of land based stations of lightning detectors (Morales et al., 2007). One of these land stations is in operation at Larnaka Airport meteorological station, on the southeast coast of Cyprus. ZEUS has a very good coverage of the area of the east Mediterranean and yields quite reliable lightning data which can be used in several applications (see for example Katsanos et al., 2007). The system is administrated and the data are archived by the National Observatory of Athens (NOA), in Greece.

For the purpose of identifying possible relationships between lightning activity and rainfall, lightning data (provided by NOA) for three rain events that caused local flooding in Cyprus were spatially and statistically related to respective rainfall measurements from the rain gauge network of the Cyprus Meteorological Service; this network of rain gauges is shown in Fig. 1. The study area is the area of the is-

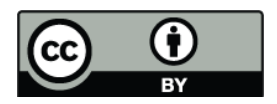

Correspondence to: S. C. Michaelides (silas@ucy.ac.cy) land of Cyprus and its surrounding sea; this was subdivided into squares in order to apply our rectangular grid based approach, as illustrated in Fig. 2. For each rain event, the daily and hourly mean and maximum rainfall rates were calculated as well as the daily and hourly number of lightning counts corresponding to each square.

The present study was undertaken within the framework of the research project FLASH (Observations, Analysis and Modeling of Lightning Activity in Thunderstorms, for use in Short Term Forecasting of Flash Floods - http://www. flashproject.org/). One of the objectives of FLASH is to use lightning activity as a proxy for convective rainfall. However, in order to adopt any methodology for such an approach, one needs to investigate the relationship between these physical parameters. In thunderstorms, a correlation between the temporal evolution of lightning activity and rainfall is supported by many studies (e.g. Ezcurra et al., 2002). It is generally accepted that for the vast majority of the studied thunderstorms an increase in rain generally corresponds to an increase in lightning activity. Furthermore, cloud-toground (CG) flashes are generally found to occur close to the heaviest precipitation (Soula et al., 1998; Soula and Chauzy, 2001). Also, many studies reveal a time-lag of a few minutes between lightning activity and rain initiation (Soula et al., 1998), or between the peak flash rate and the maximum rain rate (Piepgrass et al., 1982; Altaratz et al., 2003).

The present paper reports the preliminary results from an investigation that was carried out in order to test the rectangular grid-box methodology together with various filtering and time-lag schemes which were applied to the data used.

\section{Datasets}

The study area is bounded by meridians $32^{\circ} \mathrm{E}$ and $34.5^{\circ} \mathrm{E}$, and parallel circles $34.4^{\circ} \mathrm{N}$ and $35.8^{\circ} \mathrm{N}$. The rainfall data were obtained from 33 rain gauges belonging to the network

Published by Copernicus Publications on behalf of the European Geosciences Union. 


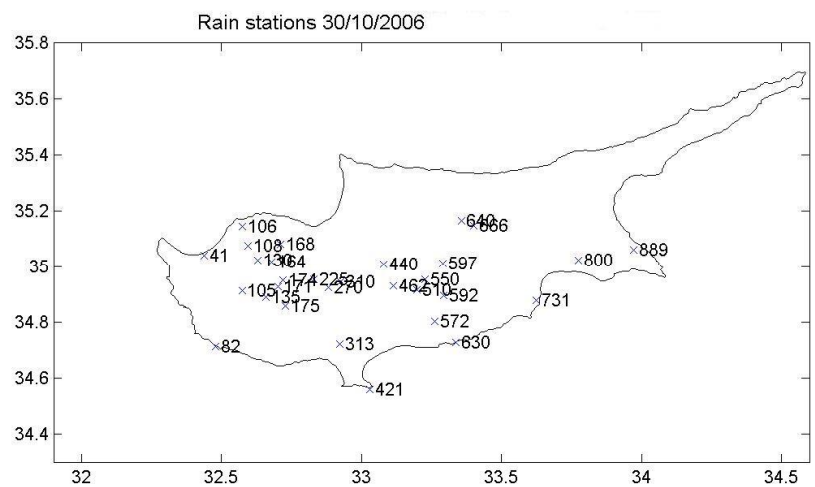

Fig. 1. The rain gauge network of the Cyprus Meteorological Service used for (crosses represent the position and numbers the local identity of the stations).

of the Meteorological Service of Cyprus. The network is shown in Fig. 1 but depending on the case, the stations used were limited to those for which data existed; data from malfunctioning stations were not taken into consideration. The lightning data were detected and recorded by the ZEUS system and were provided by NOA (an assessment of the performance of the ZEUS system has been presented recently by Morales et al., 2007).

\section{Methodology}

The three stages that were pursued for reaching a methodology that takes into consideration both the lack of an adequately dense rain gauge network and the time association between lightning occurrence and rain rates are presented below. It will be shown that one can enhance the complexity of the regression-based methodology by introducing appropriate filters to rainfall and lightning measurements.

In the first stage, the study area was divided into 12 squares, each having dimensions of $0.4^{\circ} \times 0.4^{\circ}$, as shown in Fig. 2. The above dimensions were chosen after a series of experimentations such that the squares share as many as possible of the available rain gauges and lightning activity data, while squares of smaller dimensions lead to a larger number of squares containig no rain gauges and/or lightning activity records. For each one of the 12 squares and for each rain event, calculations were performed in order to determine the values of the following three variables:

\section{1. the number of lightnings during the day,}

2. the average amount of rain $(\mathrm{mm})$, which is the total amount of rain divided by the number of stations that belong to the respective square,

3. the maximum amount of rain ( $\mathrm{mm})$, which is the maximum amount of rain from all the stations that belong to that square.

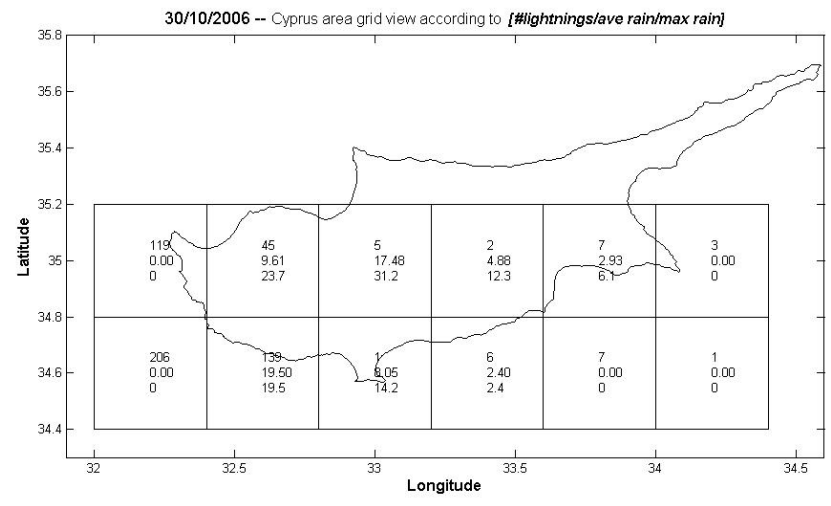

Fig. 2. The twelve squares used. The numbers in each square refer to the number of recorded lightning activity per day (top number) and the average (middle number) and maximum (bottom number), rainfall taking into consideration all the rain gauge stations that are located in the square.

Although the dimensions of the squares were selected carefully in order to include at least one rain gauge in each one of them, some squares did not have rainfall measurements because of the not satisfactory spatial distribution of rain gauges in the study area (e.g. squares with mainly marine coverage or missing rainfall data). Inevitably, the attempts to determine regression relationships between the daily counts of lightnings and rainfall (as defined above) that would produce reasonably high correlation coefficients were not promising (not shown).

In the second stage, an effort was made to expand the approach further by applying an interpolation technique, so that for all of the squares, the above three variables could be adequately determined. Interpolation on a fine grid is performed to address the lack of homogeneous rain data. Several interpolation methods were tested, but the Nearest Neighbor interpolation technique seemed to provide the most comprehensible results (other methods, such as linear optimization, were tested also but not adopted). Indeed, the Nearest Neighbor technique seemed to yield the best spatial distributions for rainfall, appropriate for the tasks undertaken in this research. In order to apply this interpolation technique, the 12 squares were transformed into a finer mesh by divining the south - north direction by 22 and the west - east direction by 62. The finer mesh consists of 1364 points arranged in such a way that in each of the original 12 squares 100 points were included (see Fig. 3). Calculations were again performed in order to determine for each one of the original 12 squares the following three variables: 


\section{1. the number of lightnings during the day}

2. the average amount of rain $(\mathrm{mm})$, which is the total amount of daily rain of all the points resulted from the interpolation, divided by the number of points that belong to the corresponding square,

3. the max amount of rain ( $\mathrm{mm})$, which is the maximum amount of rain from all the points resulting from the interpolation that belong to the corresponding square.

Applying similar regression analysis as above and following this space-refinement resulted also in low correlation coefficients (not shown); many of the squares were over the sea area, having lightning activity data but no rainfall data. The need for a more refined approach became apparent and a more scale-oriented approach was introduced.

In the third stage, the daily measurements of rainfall and lightning activity were replaced by the more time-refined hourly data sets. This time- and space-refinement seems to be more appropriate if the technique is to be used for flash flood forecasting. It was also decided to adopt a time-lag of $15 \mathrm{~min}$ between lightning and rain (other time-lags were tested but the results are not presented here). For example, the rainfall recorded from 02:00 until 03:00 UTC was associated to the lightning counts from 01:45 until 02:45 UTC. Data filtering was also applied in order to avoid misleading results. The time-lag between lightning and rainfall is supported by observations. In actual fact, there appears to be a positive time-lag between lighting and rainfall, comparable to the one adopted here: the 15 min time-lag chosen here is arbitrary but it is within an acceptable range supported by observations (Gungle and Krider, 2006). Data filtering was essential in order to remove (a) possible noise within lightning activity data (i.e., in cases of boxes with a lot of rainfall but few lightnings), and (b) small amounts of rainfall (i.e., in cases of boxes with a small amount of rainfall but several lightnings).

Having applied data filtering on the hourly measurements, for each one of the 12 squares and for every rain event, calculations were performed in order to evaluate the following three variables:

\section{1. the number of lightnings per hour during the day,}

2. the average amount of rain $(\mathrm{mm})$ per hour, which is the hourly total amount of rainfall of all the stations divided by the number of stations that belong to that particular square,

3. the max amount of rain ( $\mathrm{mm})$ per hour, which is the hourly maximum amount of rain from all the stations that belong to that particular square.

The various data filtering schemes adopted for the rainfall and lightning activity hourly data are shown in Table 1 . In the filtering schemes, the maximum rainfall was used because it

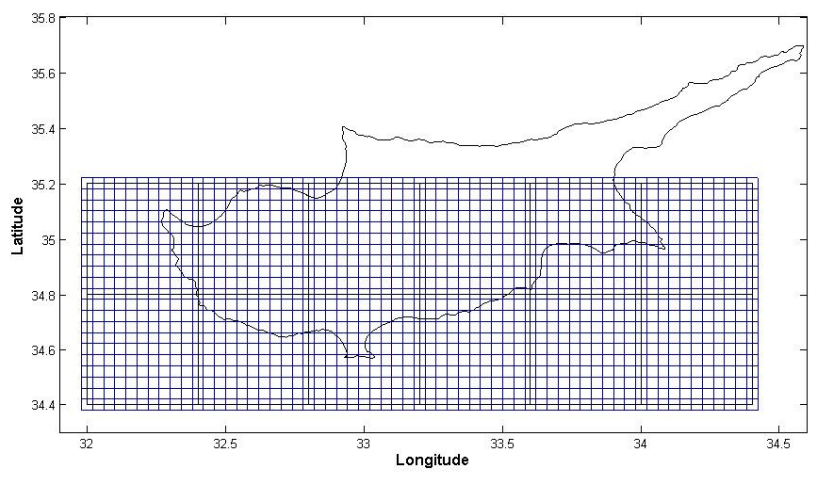

Fig. 3. The finer grid that is used for the interpolation. Each of the squares in Fig. 1 contains 100 points onto which the rain gauge data were interpolated.

is strongly related with the lightning activity. Also, in order to exclude from the calculations, low rainfall rates that are most likely not produced by convective cloud, the threshold of $5 \mathrm{~mm}$ per hour was set; rain rates below this value was not taken into consideration.

\section{Results}

The above rectangular methodology was applied to a number of rain events over Cyprus which have resulted in floods but the discussion here will be limited to only three of them. A linear regression analysis is performed between maximum hourly rainfall and the corresponding lightning counts, after data filtering is performed. In the following, results will be presented for each of these three cases, separately.

\subsection{The event of 6 November 2005}

On 6 November 2005, a surface low pressure system centered south of Cyprus developed. The position of the upper low had a westward tilt from lower to higher isobaric levels, indicating that the system was a developing one, while the increased fall in the values of geopotential height and temperature from lower to higher levels increased the instability of the air mass. This rain event has resulted in an average precipitation of $43 \mathrm{~mm}$ which corresponds to the $80 \%$ of the mean monthly precipitation. A total number of 153 lightnings were also recorded within the area of study.

For all of the seven filtering schemes, regression lines had negative slopes, while the correlation coefficients obtained small values (see Table 2). The maximum correlation values were found when we assumed that each square had at least one lightning report and rainfall of more than $5 \mathrm{~mm}$. In an attempt to interpret the above findings, it is noted that the poor results can be attributed to the high percentage of dynamic rain produced by this depression. Another reason that might affect the results is the distribution of the lighnings: it shows 
Table 1. Hourly rainfall and lightning data filtering schemes.

\begin{tabular}{|c|c|c|}
\hline $\begin{array}{l}\text { Number of } \\
\text { filtering scheme }\end{array}$ & Filtering criteria & Description \\
\hline 1 & Maximum Rain $>5 \mathrm{~mm}$ & $\begin{array}{l}\text { The pairs of rainfall-lightning where the rainfall in the box was } \\
\text { more than } 5 \mathrm{~mm}\end{array}$ \\
\hline 2 & Lightnings $>0$ & The pairs of rainfall-lightning with at least one lightning per box \\
\hline 3 & $\begin{array}{l}\text { Maximum Rain }>5 \mathrm{~mm} \text { AND } \\
\text { Lightnings }>0\end{array}$ & $\begin{array}{l}\text { The pairs of rainfall-lightning where in each box the rainfall must } \\
\text { be more than } 5 \mathrm{~mm} \text { AND the number of lightnings at least one }\end{array}$ \\
\hline 4 & Lightnings > 1 (all over Cyprus) & $\begin{array}{l}\text { The pairs of rainfall-lightning in which the number of lightnings is } \\
\text { more than } 1 \text { all over Cyprus (after summing up the lightnings of all } \\
\text { the boxes) }\end{array}$ \\
\hline 5 & Lightnings > 2 (all over Cyprus) & $\begin{array}{l}\text { The pairs of rainfall-lightning in which the number of lightnings is } \\
\text { more than } 2 \text { all over Cyprus (after summing up the lightnings of all } \\
\text { the boxes) }\end{array}$ \\
\hline 6 & $\begin{array}{l}\text { Lightnings }>1 \text { AND } \\
\text { Maximum Rain }>5 \mathrm{~mm} \text { (all over Cyprus) }\end{array}$ & $\begin{array}{l}\text { The pairs of rainfall-lightning in which the number of lightnings is } \\
\text { more than } 1 \text { AND max rain more than } 5 \mathrm{~mm} \text { all over Cyprus (after } \\
\text { summing up the lightnings of all the boxes) }\end{array}$ \\
\hline 7 & $\begin{array}{l}\text { Lightnings }>2 \\
\text { AND } \\
\text { Maximum Rain }>5 \mathrm{~mm} \text { (all over Cyprus) }\end{array}$ & $\begin{array}{l}\text { The pairs of rainfall-lightning in which the number of lightnings is } \\
\text { more than } 2 \text { AND max rain more than } 5 \mathrm{~mm} \text { all over Cyprus (after } \\
\text { summing up the lightnings of all the boxes) }\end{array}$ \\
\hline
\end{tabular}

Table 2. Regression analysis for the event of 6 November 2005.

\begin{tabular}{llll}
\hline $\begin{array}{l}\text { Number of } \\
\text { Filtering scheme }\end{array}$ & $\begin{array}{l}\text { Number of } \\
\text { lightning/rainfall, } \\
\text { pairs after filtering }\end{array}$ & $\begin{array}{l}\text { Slope of } \\
\text { regression line }\end{array}$ & $\begin{array}{l}\text { Correlation } \\
\text { coefficient }\end{array}$ \\
\hline 1 & 69 & -0.027 & 0.002 \\
2 & 43 & -0.148 & 0.026 \\
3 & 13 & -0.297 & 0.104 \\
4 & 156 & -0.073 & 0.014 \\
5 & 252 & -0.017 & 0.001 \\
6 & 62 & -0.044 & 0.005 \\
7 & 67 & -0.029 & 0.002 \\
\hline
\end{tabular}

high density to the northeast part of the area in which rainfall data are not available.

\subsection{The event of 6 and 7 February 2006}

The second rain event that was associated with an extensive low pressure system, accompanied with a cold and warm front and surface troughs, affected the areas of Central and Eastern Mediterranean and the Balkans on the 6 February 2006. The system moved to the east and amplified just to the west of Cyprus on 7 February. The depression produced extreme weather phenomena such as thunderstorms, strong winds and dust. Also, the resulting average precipitation over the study area amounted to $25 \mathrm{~mm}$ and the total number of recorded lightning recorded was 335 .
Table 3. Regression analysis for the event of 6 and 7 February 2006

\begin{tabular}{llrr}
\hline $\begin{array}{l}\text { Number of } \\
\text { Filtering scheme }\end{array}$ & $\begin{array}{l}\text { Number of } \\
\text { lightning/rainfall } \\
\text { pairs, after filtering }\end{array}$ & $\begin{array}{r}\text { Slope of } \\
\text { regression line }\end{array}$ & $\begin{array}{r}\text { Correlation } \\
\text { coefficient }\end{array}$ \\
\hline 1 & 41 & -0.26 & 0.007 \\
2 & 78 & 0.45 & 0.078 \\
3 & 21 & -0.84 & 0.066 \\
4 & 288 & 0.393 & 0.089 \\
5 & 492 & 0.418 & 0.114 \\
6 & 39 & -0.256 & 0.007 \\
7 & 39 & -0.362 & 0.013 \\
\hline
\end{tabular}

In this event, the results were found to be poor too, but better than the 6 November 2005 rain event. For the schemes with no threshold imposed on the amount of rainfall, the slope of the trend line was positive (Table 3). Also, the largest slope was noted for the situation in which all the squares under study reported lighting activity. With the application of rainfall filtering (i.e., rainfall above $5 \mathrm{~mm}$ ), the slope becomes negative. So for better results the rainfall threshold must reduced. The values of the correlation coefficient were again small with the higher values corresponding to the aforementioned schemes.

\subsection{The event of 30 and 31 October 2006}

The third depression affected the area of Cyprus on the 30 and 31 October 2006. The frontal depression formed and developed over the North Aegean, moved southeastwards and 
subsequently affected Cyprus. The advection of the airmass over the relatively warmer Mediterranean waters increased the instability and yielded an average precipitation of $47 \mathrm{~mm}$ and a total number of 2113 lightnings.

The best results were obtained for this rain event. The slope of the regression lines has positive values for all the 7 schemes applied. In five of them, the value of the slopes is greater than 1. The correlation coefficient has again small values. The highest correlation coefficients are found for the fourth and the sixth filtering schemes: $0.108,0.135$ respectively (Table 4).

\section{Concluding remarks}

The present study was motivated by the hypothesis that rainfall estimates derived from lightning observations are of potential use for short-term prediction of flash floods (see Tapia et al., 1998). In the early sixties, Battan (1965) attempted a quantification of relationships between surface rainfall and cloud-to-ground lightning activity during storms. Soula et al. (1998) supported the idea that the number of cloud-toground counts of lightning activity could bear a possible relationship to surface rainfall. This idea has been supported by observational evidence, as shown by Chèze and Sauvageot (1997). Under the assumption that the cloud microphysical processes and other environmental factors are of minor importance to this issue, the search for lightningrainfall can be tackled with simple ratios or regression relationships. However, it is clear that environmental and cloud microphysical factors have an important role in the search for relationships between lightning activity and rainfall at the surface. Indeed, Altaratz et al. (2003) have shown that lightning activity can be affected by a range of factors such as thermodynamic and orographic ones and the presence of cold frontal systems. Also, several researchers have documented a dependency of the frequency of lightnings on continental or maritime storm origin (e.g. Zipser, 1994; Zipser and Lutz, 1994): enhanced convection over continental areas yields more lightning discharges compared to convection over the sea. All of the above, and the fact that precipitation may be produced by processes that do not necessarily contribute to cloud electrification, underline the difficulty in adopting a simplistic approach in search for lightning-rainfall relationships. In spite of the above inherent difficulties, several researchers still pursue exploratory searches along this line (e.g. Ezcurra et al., 2002; Katsanos et al., 2007). Various methodologies have been adopted and the present work is just an example in which combinations of interpolation techniques, time-lags and data filtering have been explored. To the best of the authors' knowledge, the rectangular methodology described here has not been presented elsewhere.

The methodology presented has yielded correlation coefficients that were not large and the slope of the fitted regression lines had in many cases negative values (i.e., with the
Table 4. Regression analysis for the event of 30 and 31 October 2006.

\begin{tabular}{llll}
\hline $\begin{array}{l}\text { Number of } \\
\text { Filtering scheme }\end{array}$ & $\begin{array}{l}\text { Number of } \\
\text { lightning/rainfall } \\
\text { pairs, after filtering }\end{array}$ & $\begin{array}{l}\text { Slope of } \\
\text { regression line }\end{array}$ & $\begin{array}{l}\text { Correlation } \\
\text { coefficient }\end{array}$ \\
\hline 1 & 78 & 1.318 & 0.046 \\
2 & 14 & 0.988 & 0.060 \\
3 & 53 & 0.536 & 0.006 \\
4 & 528 & 1.036 & 0.108 \\
5 & 528 & 1.289 & 0.135 \\
6 & 73 & 1.192 & 0.034 \\
7 & 78 & 1.318 & 0.046 \\
\hline
\end{tabular}

increase of the lightning data the rainfall decreases). The refinement of the technique with interpolation and various carefully selected filtering schemes and time-lags seem to increase the correlation coefficients and reduce the negative sign of the slopes or, evenmore, yield positive slopes. A more careful selection of the events on the basis of thermodynamic criteria (i.e. airmass characteristics) is under way. Also, clustering of stations on the basis of their elevation and other climatic characteristics forms part of the ongoing research to study lightning/rainfall relationships along these lines.

Deeper experimentation is required with more rain events that must be carefully selected, bearing in mind that cases with few lightnings produce biased results. Also, it is possible that non-linear fitting could produce better results; one such "fitting" by using Artificial Neural Networks is under consideration along the lines examined by Michaelides et al. (2001, 2007).

Further work is also in progress that expands the experimentation with other methodologies. One such a methodology searches for relationships between rainfall variables and lightning data within a circle of varying radius around the station. The results of this series of experiments will be reported elsewhere (Michaelides, 2009).

Acknowledgements. This study was undertaken within the framework of Project FLASH, which is funded by the European Union (Sixth Framework Programme, Contract No. 036852). The lightning data were provided by the National Observatory of Athens, Greece. The authors wish to thank Joël Van Baelen for his critical comments that have led to significant improvements of the paper.

Edited by: F. Tymvios

Reviewed by: two anonymous referees

\section{References}

Altaratz, O., Levin, Z., Yair, Y., and Ziv, B.: Lightning activity over land and sea on the eastern coast of the Mediterranean, Mon. Weather Rev., 131, 2060-2070, 2003.

Battan, J. L.: Some factors governing precipitation and lightning from convective clouds, J. Atmos. Sci., 22, 79-84, 1965. 
Chèze, J. L. and Sauvageot, H.: Area - average rainfall and lightning activity, J. Geophys. Res., 102(D2), 1707-1715. 1997.

Ezcurra, A., Areitio, J., and Herrero, I.: Relationships between cloud-to-ground lightning and surface rainfall during 1992-1996 in the Spanish Basque Country area, Atmos. Res., 61, 239-250, 2002.

Gungle, B. and Krider, E. P.: Cloud-to-ground lightning and surface rainfall in warm-season Florida thunderstorms, J. Geophys. Res., 111, D19203, doi:10.1029/2005JD006802, 2006.

Katsanos, D., Lagouvardos, K., Kotroni, V., and Argiriou, A.: Combined analysis of rainfall and lightning data produced by mesoscale systems in the Central and Eastern Mediterranean, Atmos. Res., 83, 55-63, 2007.

Michaelides, S. C., Pattichis, C. S., and Kleovoulou, G.: Classification of rainfall variability by using artificial neural networks, Int. J. Climatol., 21, 1401-1414, 2001.

Michaelides, S. C., Liassidou, F., and Schizas, C. N.: Synoptic classification and establishment of analogues with artificial neural networks, J. Pure Appl. Geophys., 164, 1347-1364, 2007.

Michaelides, S. C., Savvidou, K., Nicolaides, K., Charalambous, M., and Adamou, S.: Relations between lightning and rainfall intensities during rainy events in Cyprus, Adv. Geosci., in review, 2009.
Morales, C. A., Anagnostou, E. N., Williams, E., and Kriz, J. S.: Evaluation of Peak Current Polarity Retrieved by the ZEUS Long-Range Lightning Monitoring System, IEEE Geosci. Remote Sens. Lett., 4, 32-36, 2007.

Piepgrass, M. V., Krider, E. P., and Moore, C. B.: Lightning and surface rainfall during Florida thunderstorm, J. Geophys. Res., 87(C13), 11193-11201, 1982.

Soula, S. and Chauzy, S.: Some aspects of the correlation between lightning and rain activities in thunderstorms, Atmos. Res., 56, 355-73, 2001.

Soula, S., Sauvageot, H., Molinié, G., Mesnard, F., and Chauzy, S.: The CG lightning activity of storm causing a flashflood, Geophys. Res. Lett., 25, 1181-1184, 1998.

Tapia, A., Smith, J. A., and Dixon, M.: Estimation of Convective Rainfall from Lightning Observations, J. Appl. Meteorol., 37, 1497-1509, 1998.

Zipser, E. J.: Deep cumulonimbus cloud systems in the tropics with and without lightning, Mon. Weather Rev., 122, 1837-1851, 1994.

Zipser, E. J. and Lutz, K. R.: The vertical profile of radar reflectivity of convective cells: a strong indicator of storm intensity and lightning probability, Mon. Weather Rev., 122, 1751-1759, 1994. 